\title{
Apøe Ciênci@
}

\section{EDITORIAL}

Nesta edição três artigos abordam a deficiência intelectual. O trabalho de autoria de Luciana Mascarenhas Fonseca, Aline Souza Gonçalves, Luciana Stocco, Cláudia Lopes Carvalho, Heraldo Candid Souza da Silva, José Geraldo da Silva, Ana Isabel Dorotéia Pires de Carvalho, Natalie Torres de Matos, Ricardo Valverde Jabbur, Paulo Cesar de B. Camargo, Maísa Regina Rodrigo, Maria Raimunda Rosa, Nilva Pinheiro de Andrade, Maria Bernadete Afonseca Parsons e Leila Regina de Castro, "Implicações sobre deficiência intelectual e longevidade: Projeto piloto de intervenção nos casos de senilidade" relaciona deficiência intelectual e longevidade, apontando para evidências de senilidade acelerada e intercorrência de comorbidades no processo de envelhecimento dessa população específica. Número elevado de casos de demência estão anunciados no estudo, com resultados já evidenciados na Síndrome de Down. Trata-se de um projeto piloto de intervenção, cuja relevância justifica-se na emergência de estudos científicos e práticas sociais efetivas de atenção aos idosos com deficiência intelectual, em decorrência do aumento de sua expectativa de vida nos tempos atuais.

A investigação intitulada "Educação na perspectiva do lazer na visão dos alunos com deficiência intelectual e professores do atendimento educacional especializado", que tem como autores, Suzana Alves Nogueira e Miguel Angel Garcia Bordas tem como foco a percepção de docentes e alunos de uma instituição especializada sobre a educação pelo lazer, ressaltando sua importância nos processos de aprendizagem e desenvolvimento dos educandos. O estudo revelou a forma reducionista como essa percepção ocorre na escola investigada e o modo como o lazer se mostra restrito no desenvolvimento do currículo, em detrimento de suas implicações afetivoemocionais no contexto escolar.

O estudo realizado por, Paloma Lobato Gentil Sampaio, Dayana Viana Frnaklin, Karine Lorena Moura Freire e Nedy de Sousa Pedroso, cujo título é "Perfil motor de crianças com Síndrome de Down entre 08 e 11 anos de idade na Apae de Santarém/PA" relata os resultados da aplicação de uma Escala de Desenvolvimento Motor para identificar o perfil motor de crianças com Síndrome de Down (SD) na APAE de Santarém/Pará. Objetivou identificar dificuldades e 


\section{Apøe Ciênciø}

\section{apaeciencia.org.br/revista}

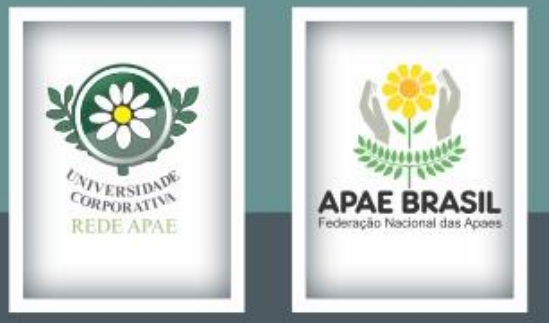

potencialidades dessa população na área, revelando predomínio de dificuldades psicomotoras moderadas, em diferentes aspectos, resultado que encontra ressonância na literatura especializada.

Erenice Natália Soares de Carvalho

\section{Editora Científica}

